\title{
Formation of the Security Service as a Tool for Ensuring the Safety and Stability of Enterprises in Modern Conditions
}

\author{
Anna Zhigunova ${ }^{1, *}$ Irina Logvinova ${ }^{1}$ Evgeniya Porublyeva ${ }^{1}$ Karina Buylova $^{1}$ \\ Zhasym Osmanov ${ }^{2}$
}

\author{
${ }^{1}$ Rostov State Transport University, Rostov-on-Don 344038, Russia \\ ${ }^{2}$ Institute of Economics Science Committee of the Ministry of Education of the Republic of Kazakhstan, Almaty 050010, \\ Kazakhstan \\ *Corresponding author. Email: ann-rgu@yandex.ru
}

\begin{abstract}
The article reflects the main problems of ensuring the safety and stability of enterprises in the real sector of the economy in modern conditions. At the same time, it is noted that for the successful functioning of the country's economy, it is necessary to ensure the competitiveness of real sector enterprises. In the modern world, due to increased competition and the emergence of various types of sanctions, as well as emerging internal and external threats, it is becoming increasingly difficult to produce competitive products. External threats have a wide range of different types of problems, such as financial, legal, information, innovative, technical, etc. In order for the company's activity to be effective, it is necessary to create its own system of economic security, because the development of the country's economy depends on each organization.
\end{abstract}

Keywords: sustainability, security, economic security, threats, risks, economic security service

\section{INTRODUCTION}

Economic security of an enterprise is the state of all types of resources that ensure their effective use and stable functioning for the dynamic scientific, technical and social development of the organization and the achievement of strategic goals.

The basis for the functioning of companies-residents of the Russian Federation in modern conditions is the creation of an effective and optimization of the characteristics of the economic security system and its management, allowing to carry out activities productively and economically improve. For a long time in transformational conditions, this issue remains significant for most enterprises, which has given rise to many definitions of the concept of "economic security".

Two main approaches are used to define the concept and essence of a company's economic security:

- economic security as the potential absence of risks and the likelihood of various threats in the course of the company's activities;

- economic security as a real system of protection against dangerous factors with the preservation of economic independence in the implementation of the interests of the enterprise, despite the impact of various adverse factors.

Given the above, we can conclude that economic security is to a certain extent the degree of protection of the enterprise from the negative impact of external and internal threats. It should be noted that the absence of a unified approach to determining the essence of economic security of an enterprise indicates that the process of ensuring and managing economic security is complex and requires a systematic approach to measuring these processes and justifying the relationships and interdependencies of such categories as competitiveness, economic potential, life cycle, financial stability and risk.

Summarizing the considered approaches and categories and applying them to industry specifics, it can be noted that the economic security of enterprises is a state of financial and economic activity that is characterized by resistance to various threats and seasonal fluctuations, as well as the ability to ensure the implementation of their own economic interests, effectively developing in discrete natural and climatic conditions. The formation of an effective system for ensuring the economic security of enterprises requires the implementation of comprehensive monitoring of its fundamental elements. The economic security of the enterprise is ensured by the security of three main objects: personnel, resources, and information from external and internal threats.

Having a competitive advantage among products, increasing the amount of ownership and profit, as well as fulfilling the production plan allows a properly developed policy of economic security of the enterprise.

\subsection{Related Work}

The most important element that is part of the enterprise security system is actions that ensure the security of any business in a highly competitive market by detecting as 
quickly as possible and at the same time weakening it from negative external and internal sources.

Ensuring the necessary level of economic security of enterprises is based on achieving a stable state in which this system actively affects and neutralizes the consequences of internal or external threats or minimizes their consequences in the context of its components such as:

- personnel;

- environmental;

- market;

- financial;

- technical and technological;

- power;

- production;

- informational;

- legal.

The main task of the company's economic security management is to guarantee effective and reliable operation in the current time and to establish sustainable development in the near future.

The purpose of ensuring the economic security of the enterprise is the need to protect the economy and personnel of the enterprise from the destructive factors of the external and internal environment. These goals include:

ensuring financial stability;

ensuring financial and technological independence and ensuring competitiveness;

protection of information security and compliance with trade secrets;

legal protection of the company from non-compliance of its activities with existing rules and regulations;

power protection of the organization's capital, property, and personnel.

Modern market features and emerging new forms of economic activity require a more thorough study of the issues of ensuring economic stability, efficiency, stability and security of the enterprise, by assessing the possible and appropriate rates of its development from the standpoint of financial and economic support that contributes to the sustainable position and development of enterprises. These provisions are relevant not only for the organizations themselves, but also for their contractors who are interested in the financial stability, well-being and reliability of partner companies.

Ensuring the sustainable development of enterprises is the basis for the stability of the market position and survival of the enterprise, provides investment, personnel, credit and market advantages. Continuous improvement of the company's stability and capacity building leads to an increase in its adaptability, independence from market changes and, as a result, a decrease in the probability of bankruptcy. The study and definition of a system of criteria, indicators and indicators that allow us to assess the degree of stability and its dynamics, as well as to identify negative factors and reduce their impact on the stability and safety of the enterprise, becomes a tool for improving the efficiency and adaptability of business structures. At the same time, the very existence of such a structure will depend on the speed and nature of the company's adaptability to changes in the external environment.
Assessment of the level of economic stability of the enterprise is an urgent, multi-faceted task, methodological approaches to solving which are disclosed in various works of Russian scientists. Thus, in the work [1] a set of approaches to the definition of "sustainability"is reflected. At the same time, it is noted that this concept is often closely related to the concept of financial stability with an emphasis on the financial results of enterprises, so the assessment is carried out according to the methods proposed by financial scientists. Some other authors identify as the main criterion of financial stability the surplus (lack) of sources of formation of reserves and costs (working capital). It often happens that this criterion is supplemented by the results of ratio analysis (ratio, ratio of financial debt (financial risk), the ratio of financial tensions, the coefficient of maneuverability on equity, ratio of circulating assets own circulating capital, etc.), reflecting the current financial position of the company. Part of the authors [2], in addition to financial stability, there are such elements of economic stability as production, market, investment and innovation, social, environmental, which take into account various aspects of the subject's activity and assess the level of its adaptability to external changes.

\section{BACKGROUND}

Given the different approaches to assessing the stability of the enterprise, we can identify several reasons that determine this process in the enterprise and determine the individual types of stability (Fig. 1)

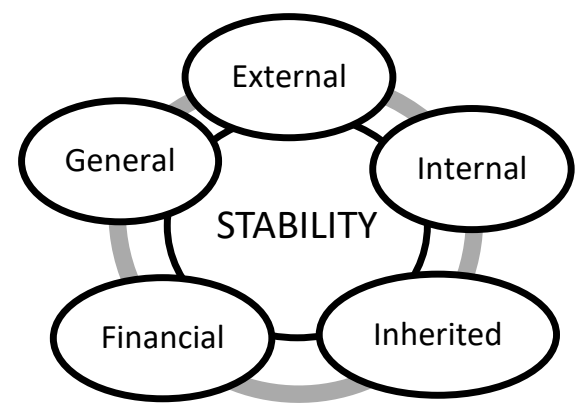

Figure 1 Types of enterprise sustainability

Internal stability is defined as the state of the subject, which characterizes the optimal production structure of production and dynamic development, which ensures the effective conduct of activities. To achieve this stability, it is necessary, first of all, to implement the principle of active response to the transformation of the financial and economic environment.

External stability is determined by the degree of stability of the external economic environment, which creates conditions for the enterprise to carry out its activities, which can only be achieved in the process of developing the legal framework and creating favorable market conditions. 
Inherited stability is manifested as a result of the formation of a financial strength reserve over a certain period, which contributes to the normalization of financial and economic activity in the event of sudden changes in the external environment or the impact of destabilizing factors and factors of unpredictability of market development.

The overall stability of the enterprise is manifested in the increase of efficiency of implemented investment projects, the level of logistical equipment and organization of production, labor and management, as well as optimizing cash flow, providing capacity-financial results and to effectively develop industrial relations system. Financial stability is based on the permanent excess of revenue over costs and characterizes the state of resources that ensure the free movement of funds and their effective use, contributing to the smooth production, technological, financial and economic activities, as well as the expansion and renewal of the enterprise itself. The main characteristics of financial stability include the ratio of the organization's own and borrowed capital, mobile and immobilized funds of the organization, the rate of capital accumulation in the implementation of such activities as current, investment, and financial, as well as the optimal provision of reserves with their own sources of formation. Determining the parameters of financial stability is considered as an economic problem in market conditions, since its lack creates the prerequisites for the enterprise's insolvency, and an excessive amount will devalue its development, inflating costs and forming excessive reserves and reserves.

Based on the above, the essence of financial stability as a factor of economic security is primarily characterized by the efficiency of formation, distribution and use of financial resources in various forms. At the same time, some researchers distinguish such types of financial stability as current, potential, formal, and real.

Numerous applied and fundamental scientific studies confirm the importance of financial security as the main element of economic security of an enterprise. Special attention should be paid to the effectiveness of management aimed at neutralizing and eliminating real threats, as well as reducing the impact of certain negative consequences of the external and internal environment. In modern conditions, the main external threats to the security and stability of the enterprise can be attributed to the lack of internal and external investment flows. In addition, ensuring the necessary level of financial security is based on data from the analysis of financial and economic activities and the degree of security of the enterprise with its own financial resources.

The efficiency, stability and safety of the enterprise is evaluated according to the following criteria:

- saving material resources and optimizing the structure of material values;

- sustainable development;

- forecasting and preventing the crisis and neutralizing factors that negatively affect the company's activities.
The system of ensuring economic security is formed in a unique and specific way for a particular enterprise, and its functioning depends directly on the legal norms and legislative acts in force in the state. For this purpose, an effective system of economic security of the enterprise, taking into account the stability of financial and economic activity, should be based on a system of measures to ensure it (Fig. 2).

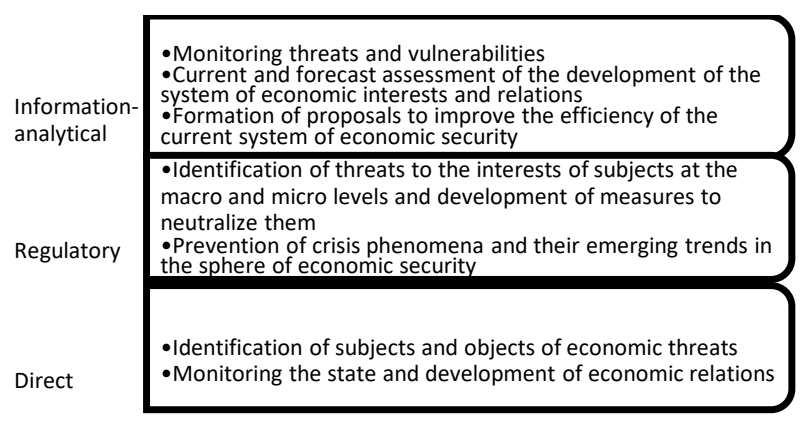

Figure 2 System of measures to ensure the safety and stability of enterprises

Summing up the above, it should be noted that each company in the formation of the economic security system will be specific. All components of the enterprise's economic security, especially personnel security, will have an impact on achieving a sufficient level of security, since it is the starting point for activating other elements of the economic security system that have a complementary nature of the relationship.

In the difficult conditions of the Russian economy for enterprises (unfair competition, raider attacks, and many other internal and external threats), there is an urgent need to confront many factors. These issues should be addressed by specialists of the economic security services.

The economic security service is a special unit in an enterprise that has its own structure, created to protect against internal and external threats.

The purpose of creating an economic security service is to achieve stability of operation and create growth prospects for the enterprise, as well as to provide favorable conditions in a competitive environment through a variety of specific functions that this service performs.

The company's economic security service performs a number of the following functions:

control - monitors both the financial activities of the company and the compliance of the staff, namely administrative requirements, it is important to monitor compliance with non-disclosure of trade secrets and rules in order to identify violations for subsequent action;

organizational - to detect potentially dangerous and existing internal and external risks that may arise in the absence of a detailed distribution of responsibilities;

economic or financial-control by the security service in the field of financial security;

administrative - installation, support and maintenance of economic security measures at the enterprise, as well as the 
creation of job descriptions that serve to distribute responsibilities and financial responsibility among the staff; technical-equipping with innovative technical tools that allow you to control and prevent not only economic, but also other types of threats;

HR policy-creating a HR policy and monitoring its compliance;

accounting-recording and distribution of data on internal and external threats of the enterprise;

analytical - a thorough study of the state of economic security, forecasting further development with proper planning.

In order to create its own economic security service, management must adequately assess its capabilities, that is, the financial side of the issue and directly the feasibility of creating an additional Department, but practice shows that the cost of protecting against threats is lower than the cost of quickly eliminating various types of threats and risks.

When creating an economic security service, it is necessary to develop competent stages for its formation, which will be implemented in the following sequence:

defining goals and making a decision to create a structure; define the tasks and functions of the security service; development of regulations for this Department; personnel selection;

creation and subsequent operation of the service; monitoring the activities and performance of the security service

In the process of functioning, a significant role is played by the skilful placement of security personnel by the head, the distribution of rights, powers and responsibilities, which allows for the effective operation of the unit. An important factor in improving the efficiency of the economic security service is a flexible system of incentives for employees of the service, depending on the results of their work [3].

One of the effective tools that the economic security service can develop and use for the efficiency of any enterprise, namely for evaluating the performance of future partners, will be scoring, a computer program that uses various mathematical and statistical techniques and data to process the request made.

Scoring or scoring program is a system of rapid evaluation of a client based on a publicly available paid online database that allows you to automatically "count points" from the questionnaire and give a result about the reliability or Vice versa of a potential client (future debtor). The security officer, based on the scoring score, decides whether to cooperate with this client or refuse it.

Scoring is a rapid assessment that reveals the following indicators:

financial condition of the organization (revenue, net profit, company assets, etc.);

payment of taxes;

courts;

risks and negative facts;

business activity - information that is reflected in this section helps to further confirm the actual activity of the company, for example, participation in tenders, the presence of a website, advertising, open vacancies and other signs of business activity, indicate that the organization really works and is created for statutory purposes; conclusion-a calculation is made of signs that indicate either the reliability or unreliability of the company at the time of verification. The rating of the company is given, the opinion of the SEB employee is expressed, and the risks and negative facts of potential customers are prescribed.

\section{CONCLUSION}

All directions and stages of economic activity in modern market conditions carry uncertainty, risks and threats that are associated with the external and internal environment of any enterprise.

Thus, for the normal functioning of the enterprise, it is necessary to know the threats and risks in order to prevent them in time. Today, companies face a huge number of problems of various types. This is due not only to the General level of economic condition of the Russian Federation, but also to factors related to ensuring the economic security of organizations.

The level of economic security depends on how effectively the company's management and specialists working in the field of economic security can prevent potential threats, as well as eliminate their consequences in time. Systematic monitoring of the economic security system in the context of its individual elements is based on the implementation of standard schemes, procedures and actions that directly identify risks and threats and develop timely preventive measures aimed at their neutralization, which will ensure stable long-term development of enterprises.

To ensure the economic security of an enterprise, it is necessary to create a security system correctly both from a legal point of view and from an economic point of view (costs) - that is, an economic security service that will monitor the achievement of strategic goals and plans, avoid external and internal threats, predict potential and possible risks, and minimize costs and losses that may arise from negative factors.

\section{REFERENCES}

[1] Kuzmenko O. V., Gritsenko E. V. Economic essence of production stability, Scientific and methodological electronic journal "Concept", 2016, T. 40, Pp. 35-38. - URL: http://ekoncept.ru/2016/56895.htm.

[2] Konyashova A. V., Merzlikina G. S. Methodology for assessing the level of economic sustainability of enterprise development, Business. Education. Right. Bulletin of the Volgograd Institute of business, 2012, No. 4(21), Pp. 174-179.

[3] Glotin I. M. Organizational-economic mechanism of countering information threats, journal of Creative economy, 2019, Volume 13, No. 11, pp. 2227-2236, doi: 10.18334/ce.13.11.41292. 